\title{
Studies about the State of Perceived Stress and Determining Risk Factors; case of Yemeni Students community Residing in Morocco.
}

\author{
Abdulrahman taresh yahya OMAIR ${ }^{1,2}$; Abderrahim BAKKALI1 ${ }^{2}$; Norelhouda AROUI ${ }^{2}$; Malika RAFIQ ${ }^{2}$ \\ Abdelmajid SOULAYMANI ${ }^{2}$ and Aberrazzak KHADMAOUI1 ${ }^{2}$. \\ ${ }^{1}$ Faculty Of Science, University Ibn Tofail; Yemen. \\ ${ }^{2}$ Biology And Health Laboratory; Biology Department Faculty Of Science, University Ibn Tofail; Kénitra Morocco
}

\begin{abstract}
Stress qualifies both a constraining situation but also the physiological process put in place by our body to adapt it. However, the students' period is characterized by difficulties which make this behavior very widespread. The aim is to study the state of psychological health, and determining factors. the study is carried out on 197 (80.2\% of men), studying in Moroccan higher education establishments. The stress test applied is Sheldon Cohen's, (1983) based on 10 items with 5 point ratings from "never" to "very often". The average age of the respondents is $32.84 \pm 0.586$ years,. The average length of residence is $4.74 \pm 0.178$ years $(66 \%$ of these students are married). In addition, the distribution of the respondents' scores shows a prevalence of $57.7 \%(n=113)$ in this category see life as a perpetual threat. The chi2 independence shows that only age has a significant influence on perceived stress (chi2 $=7.665 ; p<0.05$ ). Indeed, $61.66 \%$ of respondents aged less than 35 years showed a perpetual threat against $51.31 \%$ were over 35 years old. Then, the Yemeni authorities must provide support sessions for new students about French language learning, orientation on Moroccan social and cultural life and.
\end{abstract}

Keywords: behavior - prevalence - determining factors - Yemen

\section{1.Introduction}

Student's life, for a majority, is one of the most relaxing and fulfilling periods of life. In contrast, young people at this age are most likely exposed to behavioral illnesses such as stress and anxiety. Obviously, the stress of young people is above all an accumulation of worries which causes for $70 \%$ of them to feel overwhelmed by their daily lives[1]. In Morocco, 25 years ago, the number of foreigners enrolled in various higher education institutions reached the bar of 20,000 students[2]. The obstacles and challenges encountered by these foreign students can contribute to weakening them psychologically and socially, among these factors we cite linguistic obstacles, financial constraints, difficulties in adapting to the education system, lack of peer support, etc[3]. These barriers have a direct impact on learning and success in higher education[4;5].
Indeed, some international students come from countries and cultures where mental illness is more strongly marked out and where care is less accessible and considered less "acceptable"[6]. Faced with these constraints, the student must develop certain protective factors such as social commitment and sociability[7]. These authors, for their part, offer ways for action on the psychological well-being of foreign students, such as Educational, Community and Psychosocial.

In Morocco, the Yemeni community represented by students is 367 studying in different Moroccan educational establishments[8]. These students face many socio-economic and educational challenges due to the conditions in Yemen. The objective of this work is to develop the mental health status Yemeni students residing in Morocco as well as the determination of socio-demographic factor of stress. 


\section{2. Material and Method}

\subsection{Population and study area}

This is a cross-sectional study carried out during 2017 concerns 197 Yemeni students living in three Moroccan zones (Rabat / sale / kenitra); (Tangier / Tetouan) and Grand casa Blanca. The choice of respondents was free and random and concerns both sexes (158 male and 39 female).

\subsection{Exploitation tool (questionnaire)}

Table 1. Definition of the perceived stress items
The choice was set on the Perceived Stress Questionnaire published by psychologist 9;10. This test assesses how stressful a person overall perceives situations in his life. This test is made up of 10 items with a 5-point rating from "never" to "very often (items 4, 5, 7, 8 are reversed). A telephone conversation took place with each student to explain the objective and interest of the study as well as the ethical aspects, including the volunteering and anonymity of this survey, and to set an appointment to complete the questionnaire (table 1).

\begin{tabular}{|l|l|}
\hline 1 & Have you been disturbed by an unexpected event? \\
\hline $\mathbf{2}$ & Did you find it difficult to control the important things in your life? \\
\hline $\mathbf{3}$ & Did you feel nervous or stressed? \\
\hline $\mathbf{4}$ & Did you feel confident in dealing with your personal issues? \\
\hline $\mathbf{5}$ & Did you feel that things were going the way you wanted? \\
\hline $\mathbf{6}$ & Did you think you couldn't take on all the things you had to do? \\
\hline 7 & Were you able to control your nervousness? \\
\hline $\mathbf{8}$ & Did you feel you were in control? \\
\hline $\mathbf{9}$ & Have you felt irritated because things were beyond your control? \\
\hline 10 & Did you find that the difficulties accumulated to such an extent that you could no longer control them? \\
\hline
\end{tabular}

Interpretation of scores:

This table shows that, less than 21 (knows how to manage stress); between 21 and 26 (generally able be to cope with stress) and greater than 26 (perpetual threat).

\subsection{Statistical Analysis}

\section{Results}

\subsection{Socio demographic}

characteristics of the Yemeni

population studied

The distribution of Yemeni respondents $(80.2 \%$ of male) by zone shows that $62.94 \%$ reside in the Rabat
After filtering the data collected, we worked on the statistical analysis of the items (mean score; standard deviation, frequency, etc.) and joint analyzes such as the chi2 independence test with 5\% error.

Table 2. Socio $\neg$ demographic characteristics of the respondents 


\begin{tabular}{|c|l|l|}
\hline variable & modality & frequency \\
\hline \multirow{3}{*}{ City } & Rabat./Sale/kenitra & $\mathbf{6 2 , 9 4 \%}$ \\
\cline { 2 - 3 } & Tanger/Tetouan & $\mathbf{1 8 , 7 9 \%}$ \\
\cline { 2 - 3 } & Casa Blanca & $\mathbf{1 8 , 2 7 \%}$ \\
\hline \multirow{2}{*}{ Gender } & Men & $\mathbf{8 0 , 2 \%}$ \\
\cline { 2 - 3 } & Women & $\mathbf{1 9 , 8 \%}$ \\
\hline \multirow{2}{*}{ Age } & $<45$ year & $\mathbf{7 4 , 1 1 \%}$ \\
\cline { 2 - 3 } & $>45$ year & $\mathbf{2 5 , 8 9 \%}$ \\
\hline \multirow{2}{*}{ Marital status } & Married & $\mathbf{6 6 \%}$ \\
\hline \multirow{2}{*}{ Period of residence } & Single & $\mathbf{3 4 \%}$ \\
\cline { 2 - 3 } & $<5$ years & $\mathbf{5 0 \%}$ \\
\cline { 2 - 3 } & $>5$ years & $\mathbf{5 0 \%}$ \\
\hline
\end{tabular}

\subsection{Perceived Stress Scale: Perceived Stress Scale, PSS}

The study of the reliability of the test shows the Cronbach index reaches 0.780 with avalue of 3.36 and that the two axes absorb $67.2 \%$ of the total variation. The table below presents the results of answer choices. Indeed, less than $20 \%$ of people answered quite often to often for items one (During the last month how many times have you been disturbed by an unexpected event). Also in the case question three During the last month how many times have you felt nervous or stressed?, 6 In the last month, how often have you felt that things were going the way you wanted them to. In addition to8, in the past month, how often have you felt that you were in control? and 10- In the past month, how many times have you found that the difficulties got so much that you couldn't control them? . However, between 20 and $30 \%$ of the people surveyed answered often for items 2 (During the last month how many times did it seem difficult to you to control the important things in your life?); 5 (In the past month how often have you felt that things were going the way you wanted?) And 9 (In the past month how often have you felt irritated because of events were beyond your control?). At the end of the questionnaire, more than $30 \%$ answered often for items for (During the last month how often did you feel confident to take charge of your personal problems?) for question seven (During the last months how many times have you been able to control your nervousness)

Table 3. Valid percentage of item choices

\begin{tabular}{|c|c|c|c|c|c|c|}
\hline item & parameter & Never & Almost Never & Sometimes & Often Enough & Often \\
\hline \multirow[t]{2}{*}{1} & Frequency & 26 & 41 & 90 & 32 & 7 \\
\hline & Percent & 13,3 & 20,9 & 45,9 & 16,3 & 3,6 \\
\hline \multirow[t]{2}{*}{2} & Frequency & 39 & 33 & 65 & 39 & 20 \\
\hline & Percent & 19,5 & 16,5 & 32,5 & 19,5 & 10,0 \\
\hline \multirow[t]{2}{*}{3} & Frequency & 35 & 59 & 64 & 26 & 12 \\
\hline & Percent & 17,5 & 29,5 & 32,0 & 13,0 & 6,0 \\
\hline \multirow[t]{2}{*}{4} & Frequency & $\mathbf{0}$ & 68 & 51 & 27 & 50 \\
\hline & Percent & $\mathbf{0 , 0}$ & 34,0 & 25,5 & 13,5 & 25,0 \\
\hline 5 & Frequency & 19 & 51 & 69 & 34 & 23 \\
\hline
\end{tabular}




\begin{tabular}{|c|c|c|c|c|c|c|}
\hline & Percent & 9,5 & 25,5 & 34,5 & 17,0 & 11,5 \\
\hline \multirow[t]{2}{*}{6} & Frequency & 35 & 44 & 80 & 25 & 12 \\
\hline & Percent & 17,5 & 22,0 & 40,0 & 12,5 & 6,0 \\
\hline \multirow[t]{2}{*}{7} & Frequency & $\mathbf{0}$ & 76 & 46 & 37 & 37 \\
\hline & Percent & 0 & 38,0 & 23,0 & 18,5 & 18,5 \\
\hline \multirow[t]{2}{*}{8} & Frequency & 37 & 66 & 61 & 32 & $\mathbf{0}$ \\
\hline & Percent & 18,5 & 33,0 & 30,5 & 16,0 & $\mathbf{0}$ \\
\hline \multirow[t]{2}{*}{9} & Frequency & 34 & 58 & 51 & 36 & 17 \\
\hline & Percent & 17,0 & 29,0 & 25,5 & 18,0 & 8,5 \\
\hline \multirow[t]{2}{*}{10} & Frequency & 60 & 53 & 48 & 24 & 11 \\
\hline & Percent & 30,0 & 26,5 & 24,0 & 12,0 & 5,5 \\
\hline
\end{tabular}

Principal component analysis shows that the two axes 1 and 2 alone absorb $41.83 \%$ of the total variation, with an average inertia of 2.75 (Figure 1).

The projection of the items in the space delimited by axes 1 and 2 made it possible to classify these items into two groups.

- The first group is located on the positive side of axis 1 and is made up of items 1, 3.9 and 10 .
This axis shows that people who are disturbed by an unexpected event, they feel irritated because the events were out of their control

- The second group is located on the positive side of axis 2 is defined by items 4 and 7 . This axis is defined by means that people who feel confident in taking charge of their personal problems are able to control their nervousness.

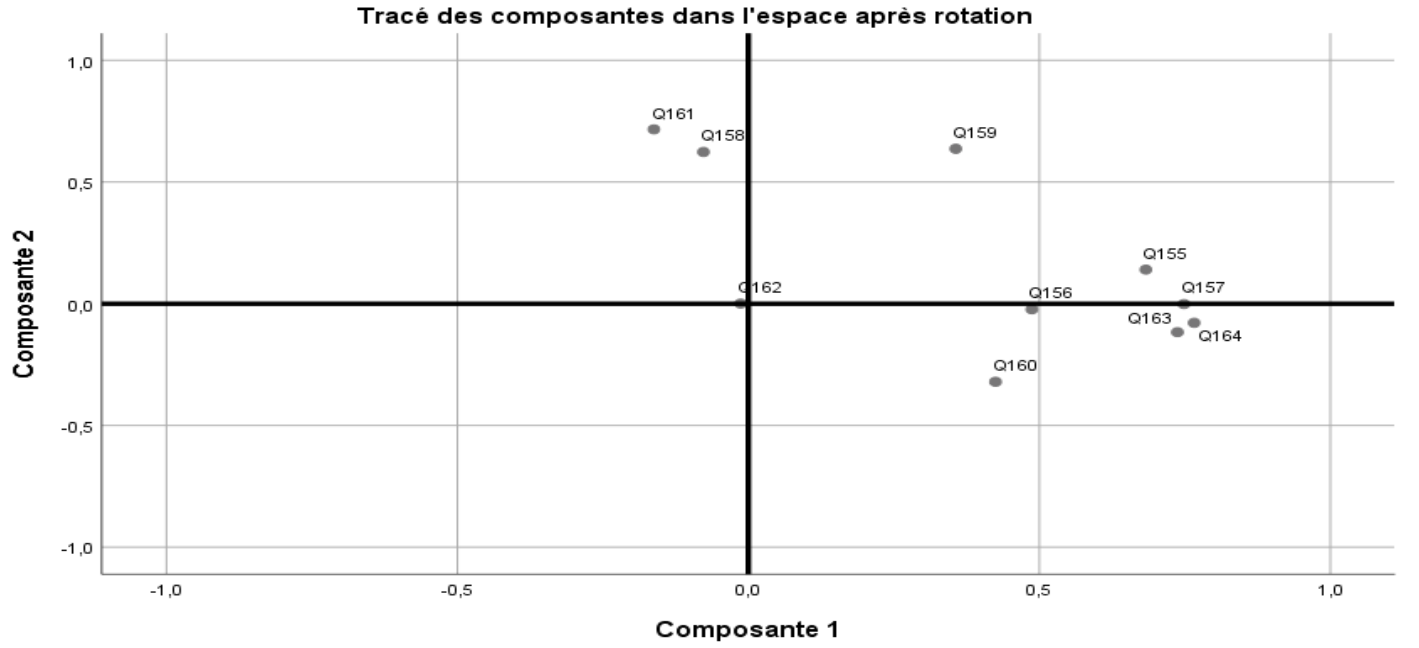

Figure 1. The distribution of respondents by score shows that.

$7.7 \%(n=15)$ of respondents have a score below 21 , which means that these people know how to manage their stress, who know how to adapt and for whom there are always solutions. $34.7 \%(n=68)$ of the respondents had a score between 21 and 26, that is to say that these people generally know how to cope with stress, but there are a certain number of situations that they do not know not manage. Sometimes she has a feeling of helplessness which leads to emotional disturbances. She can break out of this sense of helplessness by learning strategies for change. Inspit of, 57.7\% $(n=113)$ of the respondents obtained scores above 26 . These people see life as a perpetual threat: they have the feeling of 
being subjected to most situations and of being unable to do anything other than to undergo them. This strong sense of helplessness linked to their representation of life can tip it into illness. Working on his thought pattern is desirable as well as a change in the way he reacts.
The chi2 independence test (Table 4), shows that only theage has a significant influence on perceived stress (chi $2=7.665 ; \mathrm{p}<0.05)$. Indeed, $61.66 \%$ of respondents aged less than 35 years showed a perpetual threat against $51.31 \%$ were over 35 years old.

Table 4. Chi-square test of independence between categories of perceived stress and sociodemographic factors

*: significant difference at $\mathbf{5 \%}$

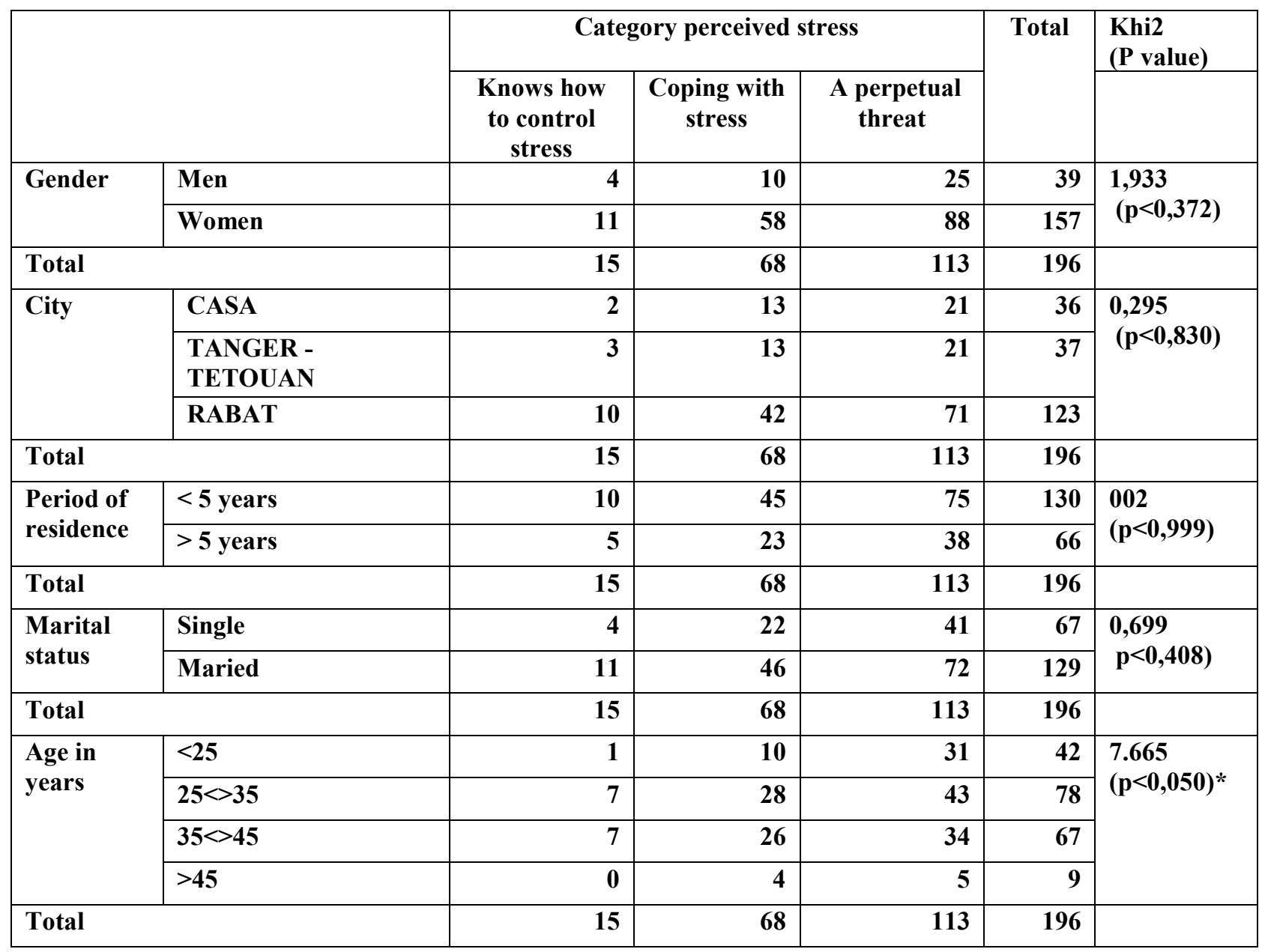

\section{Discussion}

In Morocco, the Yemeni student community finds itself stuck in their place of residence. Indeed, the lack of security in Yemen, many people are still struggling to earn a living and support their families. Faced with this situation, students are unable to get in touch with their families, which remain the only source of funding or benefit from the scholarship granted by the Yemeni government. Add to this the usual problems (rent, food, activity, transport ...). This situation finds the adequate ground for the appearance of certain psychological behaviors such as stress, depression, anxiety... ..etc. Our study is carried out on 197 students residing in three Moroccan zones. The results of the prevalence of the united state of stress show that $57.7 \%(n=113)$ of the respondents obtained scores greater than $26[9,10]$. These people see life as a perpetual threat, they feel they are suffering most in situations and not being able to do anything but endure 
them. This strong sense of helplessness linked to their representation of life can tip it toan illness. Working on his thought pattern is desirable as well as a change in the way he reacts.

According to a study by[11], it shows the importance of socioeconomic background in the academic success and mental stability of students. Also, according to a study conducted by [12] on medical students, it shows that the average stress is $24 \pm 7.18$. Furthermore, a study conducted in Tunisia by[13], a perceived stress level was high at $36.4 \%$ among medical students. In a new study published on January[14], nine in ten students report being stressed "at least once a year. A quarter say they are stressed throughout the year, and more worryingly, $22 \%$ (27\% of female students) say they have had thoughts of suicide in the past. According to [14] and according to studies carried out by[15], the causes of this stress are multiple: examination periods ( $94 \%$ of respondents, including $50 \%$ permanently), the studies themselves $(82 \%$, including $27 \%$ permanently) or guidance (71\%, including $25 \%$ permanently). Digital tools, and mainly smartphones, appear to have an impact on the feeling of perceived stress. Students seem to be aware of their impact on their ability to concentrate and the quality of their sleep. 39\% admit to being on constant alert for this reason. 5. 5.

\section{Conclusion}

The study that we carried out with Yemeni nationals residing in Morocco, mainly students, made it possible to detect certain risk factors which are directly or indirectly linked; above all, in their financial state given the conditions of war in the country of yemen, which makes communication difficult. adding to this the factors linked to the conditions of their daily life such as (food, language of study, residence ...)

\section{References}

1. M. Leroux, Stress:un quotidien pour une majorité d'étudiants français. vie étudiante (2020)

2. AMCI (Agence Marocaine de Coopération Internationale), relevant du Ministère des Affaires étrangères et de la Coopération transmet des dossiers au Ministère de l'Enseignement Supérieur, de la Recherches Scientifique et de la Formation des Cadres/ Direction de la Coopération et du Partenariat. (2014/2015)
3. CICMH (Centre for Innovation in Campus Mental Health -Supporting International Students. (2018)

4. J . Hyung ,T. Madon, B. Quinn, S. Lustig. Mental Health Need, Awareness, and Use of Counseling Services Among International Graduate Students. Journal of American College Health.; 56(2), (2010)

5. C.Dibble, Addressing the well-being and mental health of international students on campus. Vancouver, British-Colombia Council for International Education (2019)

6. C. Munn, Why are so many students struggling with their mental health ?University Affairs / Affaires universitaires (2019)

7. B. Gallais, N. Arbour, et Bikie BN. L'adaptation psychologique chez les étudiants internationaux. Journée de la recherche Mémoire Vive. Cégep de Jonquière (2019)

8. https://www.ysum.org/27. union des étudiants yéménites au Maroc (2021)

9. S . Cohen, T. Kamarck, and R. Mermelstein, The PSS Scale is reprinted with permission of the American Sociological Association, A global measure of perceived stress. Journal of Health and Social Behavior ; 24 : 386-396, (1983)

10. S. Cohen and G. Williamson, Perceived Stress in a Probability Sample of the United States. S.Spacapan, and S.Oskamp, (Eds.) The Social Psychology of Health. Newbury Park, CA: Sage, (1988)

11. A. Porrovecchio, G. Di Francesco, et J. Ladner, Étudiants acteurs de leur santé? Regards multidisciplinaires. Paris, France: L'Harmattan.( 2017).

12. L . Lahlou, N. Bennan, A. Saad, A. Boufars, M. Mrabet , R. Razin , Burn out » et stress chez les étudiants en médecine de Rabat, Maroc. Revue d'Épidémiologie et de Santé Publique, 63(2):83 (2015)

13. N. Charfi, D. Trigui , J. BenThabet, K.. Hajbi, N. Zouari, L. urZouari , M. Mohamed Maale,. Etude du rapport des troubles des conduites alimentaires avec le niveau de stress et l'estime de soi chez les étudiants en médecine.La tunisie Medicale. 93(11):720-724, (2015)

14. E.Bellanger, 9 étudiants sur 10 victimes de stress, selon la SMEREP. Le quotidien de la medecine. (2019)

15. L.R. Hadrien. Moins de budget et des étudiants plus stressés: la SMEREP inquiète.. Vie étudiante Santé : se protéger. (2009) 